\title{
Utilização do Bagaço de Cana-de-Açúcar em Dietas com Elevada Proporção de Concentrados para Novilhos Nelore em Confinamento
}

\author{
Paulo Roberto Leme ${ }^{1}$, Saulo da Luz e Silva ${ }^{2}$, Angélica Simone Cravo Pereira ${ }^{2}$, \\ Soraia Marques Putrino ${ }^{2}$, Dante Pazzanese Duarte Lanna ${ }^{3}$, José Carlos Machado Nogueira Filho ${ }^{4}$
}

\begin{abstract}
RESUMO - O objetivo deste trabalho foi avaliar o desempenho e características de carcaça de bovinos submetidos a dietas de alto concentrado contendo 15, 21 ou $27 \%$ da matéria seca em bagaço de cana-de-açúcar. Foram utilizados 24 novilhos Nelore, com peso médio em jejum de $279 \mathrm{~kg}$ e 24 meses de idade, confinados por um período de 98 dias. Não foram observados efeitos significativos para as características de ganho médio diário (média $=1,461 \mathrm{~kg}$ ) e eficiência alimentar. Foi observado efeito linear entre matéria seca ingerida e níveis de bagaço, com maior consumo nos tratamentos com menor percentagem de bagaço. Consistente com o comportamento do consumo, o peso do fígado também apresentou efeito linear, em função dos níveis de bagaço, sendo maior nos tratamentos com maior proporção de concentrado. As características peso de carcaça quente, gordura renal e pélvica, área de olho de lombo e espessura de gordura subcutânea não diferiram entre os tratamentos. Entretanto, observou-se comportamento linear do rendimento de carcaça, em função dos níveis de bagaço, sendo maior nos tratamentos com maior proporção de concentrado, consistente com o nível energético da ração. Os resultados indicam a viabilidade do uso de 15 ou $21 \%$ de bagaço como único volumoso, em dietas com elevada proporção de concentrado contendo milho, polpa de citrus e farelo de soja para novilhos Nelore em confinamento.
\end{abstract}

Palavras-chave: bagaço de cana, bovinos, confinamento, dietas com alto concentrado, Nelore

\section{Levels of Sugarcane Bagasse in Diets with High Concentrate for Nellore Steers in Feedlot}

\begin{abstract}
The objective of this work was to evaluate the performance and carcass characteristics of cattle fed high concentrate diets containing 15, 21 or $27 \%$ of sugarcane bagasse in the dry matter. Twenty-four Nellore steers with $279 \mathrm{~kg}$ of shrunk body weight and 24 months of age, two per pen, were fed for 98 days. No significant effects were observed for average daily gain $(\mathrm{mean}=1.461 \mathrm{~kg})$ and feed efficiency among the treatments. It was observed a linear effect between dry matter intake and levels of bagasse, with greater intake in treatments with lower proportion of bagasse. Consistent with intake, the liver weight presented linear association with bagasse levels, with higher weight in treatments with more concentrate. The hot carcass weight, kidney, pelvic, heart and inguinal fat, ribeye area and fat thickness were no different between treatments. However, it was observed a linear association between dressing percentage and bagasse levels, with higher percentage in treatments with more concentrate, consistent with the energy level of the diet. The results showed the viability of the use of 15 or $21 \%$ of sugarcane bagasse as the only roughage in high concentrate diets with corn, citrus pulp and soybean meal for Nellore steers in feedlot.
\end{abstract}

Key Words: beef cattle, feedlot, high concentrate diets, Nellore steers, sugarcane bagasse

\section{Introdução}

A maior parte do rebanho bovino brasileiro é constituída de zebuínos, principalmente da raça Nelore, que possui boa adaptação ao ambiente tropical, porém apresenta baixos índices de produtividade. Alguma melhora tem sido obtida com nutrição mais adequada e mudança na composição genética por intermédio de cruzamentos com raças européias.

No Brasil, dietas para confinamento tradicionalmente são balanceadas com altas proporções de volumosos, devido aos altos custos dos grãos e dos concentrados protéicos. Entretanto, quando os grãos apresentam preços vantajosos, dietas de alto concentrado tornam-se viáveis economicamente, pois proporcionam ganho de peso mais rápido, reduzindo os custos com de mão-de-obra, tornando a atividade mais rentável (Bulle et al., 1999). Entretanto, para que a atividade seja lucrativa, é necessária também elevada eficiência biológica em termos de resposta do animal.

O fornecimento de dietas com elevados teores

\footnotetext{
${ }_{1}^{1}$ Professor da FZEA/USP, Cx.P. 23, 13.630-970, Pirassununga, SP. E.mail: prleme@usp.br

2 Aluno (a) de Pós-graduação da FZEA/USP, Pirassununga, SP

3 Professor da ESALQ/USP, Piracicaba, SP - dplanna@esalq.usp.br

4 Professor Associado da FZEA/USP, Pirassununga, SP - jocamano@usp.br
} 
de concentrado para animais jovens, que apresentam boa resposta a esse tipo de alimentação, tem sido utilizado com o objetivo de intensificar o sistema de produção, pois permite o abate de animais jovens com acabamento de gordura adequado, sem prejuízos à qualidade da carne (Leme et al. 2002).

A utilização de dietas de alto concentrado é uma prática comum no sistema norte-americano de produção de bovinos. Segundo Preston (1998), essa prática caracteriza-se por rápido ganho de peso, alta eficiência alimentar e, conseqüentemente, redução no tempo para terminação e abate, menor custo de mão-de-obra e maior uniformidade do produto final. Dessa forma, há maior disponibilidade de área para a fase de cria, que absorve cerca de $70 \%$ do alimento utilizado no sistema de produção de bovinos de corte, porém essencialmente de pasto (Jenkins \& Ferrel, 1993).

Diversos autores indicam melhor utilização de dietas com maior teor de fibras por zebuínos e seus cruzamentos. Segundo Frisch \& Vercoe (1977), a melhor utilização de dietas de baixa qualidade por Bos indicus deve-se à menor exigência de manutenção.

Por outro lado, animais taurinos alimentados com forragens de alta qualidade ou forragem e concentrado consomem mais alimento em relação às suas exigências de mantença, ganhando peso mais rápido e mais eficientemente que zebuínos (O'Donovan et al., 1976). Resultados semelhantes foram relatados por Lanna (1998) e Putrino et al. (2002).

Woody et al. (1983) estudaram o efeito de diferentes níveis de grãos nas dietas de bovinos em fase de terminação e relataram que animais alimentados com dietas com $90 \%$ de grãos ganharam peso $7 \%$ mais rápido e tiveram redução de $16 \%$ no requerimento alimentar por unidade de ganho em relação a animais alimentados com $70 \%$ de grãos.

Bartle \& Preston (1991) e Bartle et al. (1994) avaliaram o efeito de níveis de volumoso sobre o desempenho e características de carcaça de bovinos. Os animais alimentados com restrição de volumoso consumiram menor quantidade de matéria seca tiveram o mesmo ganho e tenderam a ser mais eficientes em relação ao grupo alimentado com $10 \%$ de volumoso. As carcaças tiveram melhor avaliação e os custos com alimentação foram reduzidos, melhorando também a eficiência e a qualidade da carcaça, diminuindo o desperdício de alimentos.

O bagaço de cana-de-açúcar é um dos subprodutos mais utilizados como fonte de alimento para os rumi- nantes, pois, além da grande quantidade produzida, sua disponibilidade ocorre exatamente no período de escassez de forragem. Entretanto, o bagaço de canade-açúcar apresenta restrição de uso na alimentação de bovinos, pois pode reduzir o consumo total de matéria seca (Virmond, 2001).

Bulle et al. (1999) estudaram o efeito da utilização de 9,15 ou $21 \%$ de bagaço como única fonte de volumoso para tourinhos cruzados e concluíram que $15 \%$ de bagaço proporcionaram melhor desempenho dos animais.

Henrique et al. (1999), estudando o efeito do bagaço de cana-de-açúcar e silagem de milho como fonte de fibra efetiva em dietas de alto concentrado para novilhos em terminação, concluíram que o bagaço pode ser utilizado como fonte exclusiva de volumoso, embora o ganho de peso e a eficiência de conversão tenham sido menores que os observados com silagem de milho, comparados à mesma proporção de concentrado.

O objetivo deste trabalho foi avaliar o desempenho e características de carcaça de novilhos Nelore recebendo dietas de alto concentrado com 15, 21 ou $27 \%$ de bagaço de cana-de-açúcar como única fonte de volumoso.

\section{Material e Métodos}

O experimento foi desenvolvido no Departamento de Zootecnia da Faculdade de Zootecnia e Engenharia de Alimentos da Universidade de São Paulo FZEA/USP, em Pirassununga, SP. O município de Pirassununga está situado a $21^{\circ} 59^{\prime}$ de latitude Sul e $47^{\circ} 26^{\prime}$ de longitude Oeste e a uma altitude de 634 metros. O clima é considerado subtropical tipo cwa Köppen (subtropical, com inverno seco e bem definido e verão quente e chuvoso) (Oliveira \& Prado,1984).

Foram utilizados 24 novilhos Nelore, com peso médio em jejum de $279 \mathrm{~kg}$ e 24 meses de idade no final do período de 28 dias de adaptação. Os animais foram distribuídos de acordo com o peso inicial em 12 baias parcialmente cobertas, com dois animais por baia. O período de confinamento foi de 98 dias, após o período de adaptação no qual os animais receberam níveis crescentes de concentrado até atingirem 15, 21 ou $27 \%$ de bagaço de cana-deaçúcar na matéria seca.

Para o cálculo das exigências nutricionais foi utilizado o Cornell Net Carbohidrate and Protein 
System - CNCPS (Fox et al., 1992), visando atender à exigência de proteína degradável no rúmen e proteína metabolizável, bem como a exigência de peptídeos das bactérias ruminais (Tabela 1).

Diariamente foram coletadas e pesadas as sobras de alimento e duas vezes por semana foi determinada a matéria seca (MS) da sobra. Semanalmente a quantidade de alimento fornecido foi reajustada, com base no consumo da semana anterior. As pesagens foram realizadas a cada 28 dias, após jejum completo de 18 horas. A partir desses dados foram calculados o ganho médio diário (GMD), a matéria seca ingerida (MSI), a matéria seca ingerida/100 kg de peso vivo (MSI100), a matéria seca ingerida/ $\mathrm{kg}^{0,75}$ (MSIPM) e a eficiência alimentar (EA) (ganho médio diário/matéria seca ingerida). No final do período experimental os animais foram abatidos e coletados dados de peso de carcaça quente (PCQ),

Tabela 1 - Composição percentual das dietas utiliza-
das no experimento na matéria seca
Table 1 - $\begin{aligned} & \text { Percentual composition of diets used in the } \\ & \text { experiment, as dry matter basis }\end{aligned}$ Ingredientes Ingredients Níveis de bagaço de cana-de-açúcar, \% Sugarcane bagasse levels, \%

\begin{tabular}{lccc} 
& 15 & 21 & 27 \\
\hline Milho grão seco & 41,1 & 37,3 & 33,7
\end{tabular}

Dry corn grain

Farelo de soja $49 \%$

$13,6 \quad 14,0 \quad 14,2$

Soybean meal $49 \%$

Polpa de citrus peletizada $\quad 28,2 \quad 25,6 \quad 23,0$

Citrus pulp pellets

Bagaço de cana in natura $\quad 15,0 \quad 21,0 \quad 27,0$

Sugarcane bagasse

Uréia

Urea

$0,8 \quad 0,8 \quad 0,8$

Núcleo mineral

Mineral premix

Sulfato de amônia

Ammonium sulfate

Cloreto de potássio

Potassium chloride

Rumensin

Rumensin

$1,0 \quad 1,0 \quad 1,0$

$0,05 \quad 0,05 \quad 0,05$

Nutrientes (Estimados)

Nutrients (Estimated)

Proteína bruta, \%,

Crude protein, \%

Proteína degradável no rúmen, $\% \quad 9,9 \quad 9,8 \quad 9,6$

Rumen degradable protein, $\%$

NDT , $\% 1$

$T D N, \% 1$

$74,5 \quad 71,4 \quad 68,3$

\footnotetext{
${ }^{1}$ Estimado por intermédio de fórmula de Weiss et al. (1992).

${ }^{1}$ Estimated by means of Weiss et al. (1992) equation.
}

gordura renal, pélvica e inguinal (GRPI) e peso do fígado (PF). Após 24 horas de resfriamento das carcaças, foram coletados os dados de área de olho de lombo (AOL) e espessura de gordura subcutânea (EGS) na carcaça entre a 12 e $13^{\mathrm{a}}$ costelas com o auxílio de uma grade quadriculada especialmente desenhada para essa finalidade.

O delineamento experimental utilizado foi inteiramente casualizado, com oito repetições por tratamento. Os efeitos dos tratamentos foram avaliados por regressão linear por intermédio do programa SAS ${ }^{\circledR}(1990)$.

Para análise dos dados de desempenho foram utilizadas as médias dos animais por baia, enquanto que para os dados de carcaça foram analisados os dados individuais.

\section{Resultados e Discussão}

Os resultados de desempenho obtidos neste trabalho estão apresentados na Tabela 2. Não houve diferenças significativas entre os tratamentos no peso vivo inicial e no peso vivo final. Os GMD foram de 1,$51 ; 1,49$ e $1,38 \mathrm{~kg}$ nos tratamentos com 15,21 e $27 \%$ de bagaço de cana-de-açúcar, respectivamente, com tendência $(p=0,15)$ de associação linear. $O$ desempenho dos animais foi bastante elevado, sendo que as taxas de ganho de peso mantidas ao longo do experimento, até $8 \mathrm{~mm}$ de gordura, acima da média citada na literatura para bovinos Nelore.

Foi observado comportamento linear entre os níveis de concentrado, a ingestão de matéria seca e a MSI100 ( $\mathrm{p}<0,05)$, com maior ingestão nos animais alimentados com dietas com maior proporção de concentrado. A MSIPM também apresentou um efeito linear em relação ao nível de concentrado $(\mathrm{p}<0,01)$. Não foi observado efeito dos níveis de bagaço sobre a eficiência alimentar.

Lanna (1998) comenta que dados da literatura mostram respostas muito inconsistentes quando animais zebuínos são submetidos a dietas de alto concentrado, nas quais milho ou sorgo correspondem a mais de $50 \%$ da matéria seca.

Bulle et al. (1999) não encontraram diferenças significativas no GMD, MSI e EA em tourinhos com $3 / 4$ de sangue Bos taurus, recebendo 15 ou $21 \%$ de bagaço como única fonte de fibra em rações de alto concentrado. Entretanto, observaram redução na ingestão de matéria seca na dieta contendo $9 \%$ de bagaço.

Henrique et al. (1999) não observaram alteração na ingestão de matéria seca em tourinhos Santa

R. Bras. Zootec., v.32, n.6, p.1786-1791, 2003 (Supl. 1) 
Tabela 2 - Médias, coeficientes de variação (CV), equações de regressão (EqR) e coeficiente de determinação $\left(R^{2}\right)$ para as características de desempenho dos animais submetidos aos diferentes tratamentos

Table 2 - Means, coefficient of variation (CV), regression equations (EqR) and coefficient of determination $\left(R^{2}\right)$ of performance characteristics of animals in different treatments

\begin{tabular}{|c|c|c|c|c|c|c|}
\hline \multirow[t]{2}{*}{ Características } & \multicolumn{3}{|c|}{$\begin{array}{l}\text { Níveis de bagaço, \% } \\
\text { Bagasse levels, \% }\end{array}$} & \multirow[b]{2}{*}{$\mathrm{CV}$} & \multirow[b]{2}{*}{ EqR } & \multirow[b]{2}{*}{$\mathrm{R}^{2}$} \\
\hline & 15 & 21 & 27 & & & \\
\hline $\begin{array}{l}\text { Peso médio inicial, } \mathrm{kg} \\
\text { Initial body weight, } \mathrm{kg}\end{array}$ & 277 & 279 & 281 & 9,3 & & \\
\hline $\begin{array}{l}\text { Peso médio final, } \mathrm{kg} \\
\text { Final body weight, } \mathrm{kg}\end{array}$ & 423 & 424 & 416 & 7,4 & & \\
\hline $\begin{array}{l}\text { Ganho médio diário, } \mathrm{kg} \\
\text { Mean daily gain, } \mathrm{kg}\end{array}$ & 1,51 & 1,49 & 1,38 & 11,7 & & \\
\hline $\begin{array}{l}\text { Matéria seca ingerida, } \mathrm{kg} \\
\text { Dry matter intake, } \mathrm{kg}\end{array}$ & 8.3 & 7,9 & 7,5 & 8,0 & 1 & 0,22 \\
\hline $\begin{array}{l}\text { Matéria seca ingerida } / 100 \mathrm{~kg} \text { Peso vivo, } \mathrm{kg} \\
\text { Dry matter intake/100 kg of live weight, } \mathrm{kg}\end{array}$ & 2,4 & 2,3 & 2,2 & 7,7 & 2 & 0,21 \\
\hline $\begin{array}{l}\text { Matéria seca ingerida } / \mathrm{kg}^{0,75}, \mathrm{~g} \\
\text { Dry matter intake/kg. }{ }^{75}, \mathrm{~g}\end{array}$ & 104,7 & 98,7 & 95,2 & 6,8 & 3 & 0,26 \\
\hline $\begin{array}{l}\text { Eficiência alimentar, } \mathrm{kg}^{\mathrm{a}} \\
\text { Feed efficiency, } \mathrm{kg}^{\mathrm{a}}\end{array}$ & 0,190 & 0,183 & 0,183 & 7,2 & & \\
\hline $\begin{array}{l}1-\mathrm{Y}=9,2993^{* *}-0,0655^{*} \mathrm{X} \\
2-\mathrm{Y}=2,6958^{* *}-0,0179^{*} \mathrm{X} \\
3-\mathrm{Y}=116,125^{* *}-0,7917^{* *} \mathrm{X}\end{array}$ & & & & & & \\
\hline
\end{tabular}

Gertrudis alimentados com dietas de alto concentrado, quando a fonte de volumoso utilizada foi bagaço ou silagem de milho. Krehbiel et al. (2000), comparando novilhos Boran x MARC III (1/4 Angus, Hereford, Pinzgauer e Red Poll) e MARC III, alimentados com uma dieta com $95 \%$ de concentrado, em que o milho correspondia a cerca de $87 \%$ da dieta, também não observaram diferenças significativas na ingestão de matéria seca, no ganho de peso e na eficiência alimentar entre os grupos testados.

Entretanto, resultados apresentados por Putrino et al. (2002), avaliando o efeito de diferentes proporções de concentrado $(20,40,60$ ou $80 \%)$ na dieta de tourinhos Nelore e Brangus, usando como volumoso a silagem de milho, observaram redução na ingestão de matéria seca pelos animais Nelore a partir de $46,7 \%$ de concentrado na dieta (ponto de máxima da curva), enquanto para os animais Brangus essa redução ocorreu somente a partir de $57,76 \%$ de concentrado. Nas dietas utilizadas no trabalho, o milho participou em cerca de 41, 51, 64 e $77 \%$ do total da dieta (grão seco + grão da silagem).

Aparentemente, os resultados de desempenho muito positivos do presente trabalho poderiam ser explicados pela proporção de amido relativamente baixa nas dietas com apenas $15 \%$ de volumoso.

As características PCQ, GRPI, AOL e EGS não foram influenciadas pelo nível de bagaço na dieta. As características $\mathrm{PF}$ e RC apresentaram comportamento linear em função dos níveis de bagaço $(p<0,05)$, sendo maiores nos tratamentos com maiores percentagens de concentrado, consistentes com os maiores teores de energia das dietas.

Isso parece indicar que os animais que receberam maiores teores de fibra continham maior proporção de vísceras ou de conteúdo do trato gastrintestinal Como o peso do fígado e da GRPI foram menores para esses tratamentos, provavelmente o efeito foi devido ao maior conteúdo e/ou do peso do rúmen e intestinos. Esses resultados também são semelhantes aos encontrados por Bulle et al. (1999), que não observaram diferenças significativas entre tratamentos com 15 e $21 \%$ de bagaço para RC, EGS, PF, AOL, exceto para GRPI.

Entretanto, os resultados de Henrique et al (1999), utilizando dietas semelhantes, demonstraram desempenho significativamente superior quando o bagaço in natura foi substituído pela silagem de milho. Apesar dos trabalhos conduzidos por esse grupo sugerirem que níveis próximos a $15 \%$ sejam superiores a níveis mais elevados de bagaço, seria interessante compreender, por meio de estudos da fisiologia da digestão, quais as limitações existentes e se elas estão ligadas a um ambiente ruminal inadequado.

R. Bras. Zootec., v.32, n.6, p.1786-1791, 2003 (Supl. 1) 
Tabela 3 - Médias, coeficientes de variação $(C V)$, equações de regressão $(E q R)$ e coeficiente de determinação $\left(R^{2}\right)$ para as características de carcaça dos animais submetidos aos diferentes tratamentos

Table 3 - Means, coefficients of variation (CV), regression equations (EqR) and coefficient of determination $\left(R^{2}\right)$ of carcass characteristics of animals in different treatments

\begin{tabular}{|c|c|c|c|c|c|c|}
\hline \multirow[t]{2}{*}{$\begin{array}{l}\text { Características } \\
\text { Characteristics }\end{array}$} & \multicolumn{3}{|c|}{$\begin{array}{c}\text { Níveis de bagaço, \% } \\
\text { Bagasse levels, \% }\end{array}$} & \multirow[b]{2}{*}{$\mathrm{CV}$} & \multirow[b]{2}{*}{ EqR } & \multirow[b]{2}{*}{$\mathrm{R}^{2}$} \\
\hline & 15 & 21 & 27 & & & \\
\hline Peso de carcaça quente, $\mathrm{kg}$ & 247,0 & 246,6 & 235,7 & 6,8 & & \\
\hline $\begin{array}{l}\text { Hot carcass weight, } \mathrm{kg} \\
\text { Rendimento de carcaça, \% } \\
\text { Dressing percentage, \% }\end{array}$ & 58,3 & 58,2 & 56,7 & 2,1 & 1 & 0,24 \\
\hline $\begin{array}{l}\text { Gordura renal e pélvica, } \mathrm{kg} \\
\text { Renal and pelvic fat, } \mathrm{kg}\end{array}$ & 8,5 & 8,4 & 7,8 & 20,6 & & \\
\hline $\begin{array}{l}\text { Peso do fígado, } \mathrm{kg} \\
\text { Liver weight } \mathrm{kg}\end{array}$ & 5,1 & 4,7 & 4,5 & 9,9 & 2 & 0,22 \\
\hline $\begin{array}{l}\text { Área de olho de lombo, } \mathrm{cm}^{2} \\
\text { Ribeye area, } \mathrm{cm}^{2}\end{array}$ & 62,4 & 61,8 & 58,0 & 9,6 & & \\
\hline $\begin{array}{l}\text { Espessura de gordura subcutânea, mm } \\
\text { Backfat thickness, } m m\end{array}$ & 8,75 & 8,12 & 8,00 & 54,6 & & \\
\hline
\end{tabular}

\section{Conclusões}

Os resultados deste experimento confirmam a viabilidade do uso de 15 ou $21 \%$ de bagaço de canade-açúcar como única fonte de volumoso para novilhos Nelore em confinamento, alimentados com dietas com elevada proporção de concentrado, contendo milho, polpa de citrus e farelo de soja. O bagaço de cana-de-açúcar pode ser uma alternativa interessante, já que é um resíduo da agroindústria de grande excedente e baixo custo, produzido na época de confinamento e escassez de forragem.

Os resultados observados demonstram ser possível abater animais zebuínos com até $8 \mathrm{~mm}$ de gordura subcutânea e com boa eficiência alimentar.

\section{Literatura Citada}

BARTLE, S.J.; PRESTON, R.L. Dietary roughage regime for feedlot steers: reduced roughage level (2\%) during the midfinishing period. Journal of Animal Science, v.69, n.9, p.3461-3466, 1991.

BARTLE, S.J.; PRESTON, R.L.; MILLER, M.F. Dietary energy source and density: Effects of roughage source roughage equivalent, tallow level, and steer type on feedlot performance and carcass characteristics. Journal of Animal Science, v.72, n.8, p.1943-53, 1994.

BULLE, M.L.M.; RIBEIRO, F.G.; LEME, P.R. et al. Uso do bagaço de cana-de-açucar como único volumoso em dietas de alto teor de concentrado. 1. Desempenho. In: REUNIÃO ANUAL DA SOCIEDADE BRASILEIRA DE ZOOTECNIA, 36., 1999, Porto Alegre. Anais... Porto Alegre: Sociedade Brasileira de Zootecnia, [1999]. CD-ROM. Nutrição de Ruminantes. Confinamento e bovinos de corte.
FOX, D.G.; SNIFFEN, C.J.; O'CONNOR, J.D. et al. A net carbohydrate and protein system for evaluating cattle diets: III Cattle requirements and diet adequacy. Journal of Animal Science, v.70, p.3578-3596, 1992.

FRISCH, J.E.; VERCOE, J.E. Food intake, eating rate, weight gains, metabolic rate and efficiency utilization in Bos taurus and Bos indicus crossbreed catte. Animal Production, v.25, p.343-358, 1977.

HENRIQUE, W.; LEME, P.R.; LANNA, D.P.D. et al. Avaliação do milho úmido com bagaço de cana ou silagem de milho na engorda de bovinos. 1. Desempenho animal e características da carcaça. In: REUNIÃO ANUAL DA SOCIEDADE BRASILEIRA DE ZOOTECNIA, 36., 1999, Porto Alegre. Anais... Porto Alegre: Sociedade Brasileira de Zootecnia, [1999]. CD-ROM. Nutrição de Ruminantes. Confinamento e bovinos de corte.

JENKINS, T.G.; FERREL, C.L. Conversion efficiency through weaning of nine breeds of cattle. Meat Animal Research Center, 1977. p.156-157 (Beef Research, Progress Report, 447).

KREHBIEL, C.R.; KREIKEMEIER, K.K.; FERREL, C.L. Influence of Bos indicus and cattle age on apparent utilization of high-grain diet. Journal of Animal Science, v.78, p.1641-1647, 2000.

LANNA, D.P.D. Exigências nutricionais do gado de corte - O sistema NRC. In: SIMPÓSIO SOBRE PRODUÇ̃̃O INTENSIVA DE GADO DE CORTE, 1998, Campinas. Anais... Campinas: Colégio Brasileiro de Nutrição Animal, 1998. p.138-167.

LEME, P.R.; SILVA, S. L.; PEREIRA, A.S.C. et al. Desempenho e características de carcaça de animais Nelore, $1 / 2$ Caracu $\mathrm{x}$ Nelore e $3 / 4$ Caracu x Nelore confinados com dietas de alto concentrado. In: REUNIÃO ANUAL DA SOCIEDADE BRASILEIRA DE ZOOTECNIA, 39., 2002, Recife. Anais... Recife: Sociedade Brasileira de Zootecnia, 2002. CD-ROM. Nutrição de Ruminantes. Confinamento e bovinos de corte.

O'DONOVAN, P.B.; GEBREWOLDE, A.B.; KEBEDE, B. et al. Fattening studies with cross-breed (European $\mathrm{x} Z \mathrm{Zebu}$ ) bulls.

R. Bras. Zootec., v.32, n.6, p.1786-1791, 2003 (Supl. 1) 
1. Performance on diets of native hay and concentrate. Journal of Agricultural Science, v.90, p.425-429, 1978.

OLIVEIRA, J.B.; PRADO, H. Levantamento pedológico do Estado de São Paulo: quadrícula de São Carlos. II Memorial descritivo. Instituto Agronômico de Campinas IAC, 1984. 188p. (Boletim Técnico, 98).

PRESTON, R.L. Management of high concentrate diets in feedlot. In: SIMPÓSIO SOBRE PRODUÇÃO INTENSIVA DE GADO DE CORTE, 1998, Campinas. Anais... Campinas: CBNA, 1998. p.82-91.

PUTRINO, S.M.; LEME, P.R.; SILVA, S.L. et al. Desempenho de Tourinhos Brangus e Nelore Alimentados com Diferentes Proporções de Concentrado In. REUNIÃO ANUAL DA SOCIEDADE BRASILEIRA DE ZOOTECNIA, 39., 2002, Recife. Anais... Recife: Sociedade Brasileira de Zootecnia, [2002]. CD-ROM. Nutrição de Ruminantes.

STATISTICAL ANALYSES SYSTEM - SAS. SAS/STAT user's guide, Version 6, 4.ed., v.2, Cary: 1990.

VIRMOND, M. Avaliação do bagaço de cana tratado com diferentes agentes químicos através de estudos da cinética ruminal e ensaios de digestibilidade. Pirassununga: Faculdade de Zootecnia e Engenharia de Alimentos, 2001. 82p.
Dissertação (Mestrado em Zootecnia) - Universidade de São Paulo, 2001.

WEISS, W.P.; CONRAD, H.R.; PIERRE, N.R. St. A theoreticalbased model for predicting total digestible nutrient values of forages and concentrates. Animal Feed Science and Technology, v.39, p.95-110, 1992.

WOODY, H.D.; FOX, D.G.; BLACK, J.R. Effect of diet grain content on performance of growing and finishing cattle. Journal of Animal Science, v.57, p.717-726, 1983.

Recebido em: 05/09/02

Aceito em: 02/04/03 